\title{
Expression of the Sodium/Calcium/Potassium Exchanger, NCKX4, in Ameloblasts
}

\author{
Ping Hu ${ }^{a, c}$ Rodrigo S. Lacruz ${ }^{a}$ Charles E. Smith ${ }^{d}$ Susan M. Smith ${ }^{a}$ Ira Kurtz \\ Michael L. Paine ${ }^{a}$ \\ ${ }^{a}$ Center for Craniofacial Molecular Biology, Herman Ostrow School of Dentistry, University of Southern California, \\ and ${ }^{b}$ Division of Nephrology, David Geffen School of Medicine at UCLA, Los Angeles, Calif., USA; ${ }^{c}$ Center of \\ Stomatology, Tongji Hospital of Tongji Medical College of Huazhong University of Science and Technology, \\ Wuhan, PR China; ${ }^{d}$ Facility for Electron Microscopy Research, Department of Anatomy and Cell Biology and Faculty \\ of Dentistry, McGill University, Montreal, Que., Canada
}

\section{Key Words}

Amelogenesis - Enamel · Solute carrier gene - Sodium/ calcium exchanger $\cdot$ Sodium/calcium/potassium exchanger • Mouse

\section{Abstract \\ Transcellular calcium transport is an essential activity in min- eralized tissue formation, including dental hard tissues. In many organ systems, this activity is regulated by membrane- bound sodium/calcium $\left(\mathrm{Na}^{+} / \mathrm{Ca}^{2+}\right)$ exchangers, which in- clude the NCX and NCKX [sodium/calcium-potassium $\left(\mathrm{Na}^{+}\right.$/ $\left.\mathrm{Ca}^{2+}-\mathrm{K}^{+}\right)$exchanger] proteins. During enamel maturation, when crystals expand in thickness, $\mathrm{Ca}^{2+}$ requirements vastly increase but exactly how $\mathrm{Ca}^{2+}$ traffics through ameloblasts remains uncertain. Previous studies have shown that several NCX proteins are expressed in ameloblasts, although no sig- nificant shifts in expression were observed during matura- tion which pointed to the possible identification of other $\mathrm{Ca}^{2+}$ membrane transporters. NCKX proteins are encoded by members of the solute carrier gene family, SIc24a, which in- clude 6 different proteins (NCKX1-6). NCKX are bidirectional electrogenic transporters regulating $\mathrm{Ca}^{2+}$ transport in and}

out of cells dependent on the transmembrane ion gradient. In this study we show that all NCKX mRNAs are expressed in dental tissues. Real-time PCR indicates that of all the members of the NCKX group, NCKX4 is the most highly expressed gene transcript during the late stages of amelogenesis. In situ hybridization and immunolocalization analyses clearly establish that in the enamel organ, NCKX4 is expressed primarily by ameloblasts during the maturation stage. Further, during the mid-late maturation stages of amelogenesis, the expression of NCKX4 in ameloblasts is most prominent at the apical poles and at the lateral membranes proximal to the apical ends. These data suggest that NCKX4 might be an important regulator of $\mathrm{Ca}^{2+}$ transport during amelogenesis.

Copyright $\odot 2012$ S. Karger AG, Basel

\begin{tabular}{ll} 
Abbreviations used in this paper \\
\hline Hap & hydroxyapatite \\
NCKX & sodium/calcium-potassium exchanger \\
NCX & sodium/calcium exchanger \\
Slc & solute carrier gene family
\end{tabular}

Dr. Michael L. Paine

Center for Craniofacial and Molecular Biology, Herman Ostrow School of Dentistry University of Southern California, 2250 Alcazar Street

CSA103, Los Angeles, CA 90033 (USA)

Tel. +1 323442 1728, E-Mail paine@ usc.edu 


\section{Introduction}

Enamel and dentin formation both begin with an extracellular proteinaceous matrix that directs the subsequent events of hydroxyapatite (Hap) formation and biomineralization. Calcium $\left(\mathrm{Ca}^{2+}\right)$ and phosphate $\left(\mathrm{PO}^{3-}{ }_{4}\right)$ are core molecular building blocks of Hap, yet their transport from the circulation to the developing dentin and enamel matrix is poorly understood. The importance of this ionic movement is, nevertheless, well appreciated [Smith, 1998; Hubbard, 2000]. During dentin formation, $\mathrm{Ca}^{2+}$ is transported from the pulpal vascular network through the odontoblast layer, by what is believed to be a transcellular pathway, to be incorporated in the mineral phase at the interface between the nonmineralized predentin and the mineralized dentin [Linde, 1995; Tsumura et al., 2010]. Mature enamel is composed of densely packed Hap crystallites arranged into enamel prisms [Paine et al., 2001]. Despite the high mineral content of enamel, we are only starting to understand which ion transporters, including $\mathrm{Ca}^{2+}, \mathrm{HCO}_{3}{ }^{-}$and $\mathrm{Cl}^{-}$transporters, are critical to amelogenesis and thus allow for ion transport between the papillary layer and the forming enamel crystals [Hubbard, 1995, 1996, 2000; Franklin et al., 2001; Turnbull et al., 2004; Josephsen et al., 2010; Lacruz et al., 2010b; Lacruz et al., 2010c; Okumura et al., 2010; Lacruz et al., 2012b].

One of the mechanisms used by cells for $\mathrm{Ca}^{2+}$ import and export are the sodium/calcium $\left(\mathrm{Na}^{+} / \mathrm{Ca}^{2+}\right)$ exchangers, where the main function is to control $\mathrm{Ca}^{2+}$ flux across the plasma membranes and/or intracellular compartments [Quednau et al., 2004; Schnetkamp, 2004]. Members of the Slc8a and Slc24a gene families encode for $\mathrm{Na}^{+} / \mathrm{Ca}^{2+}$ exchangers. NCX proteins (NCX1, NCX2 and NCX3) are coded by 3 Slc8a genes (Slc8a1, Slc8a2 and $S l c 8 a 3$, respectively) and are bidirectional transporters capable of exchanging $\mathrm{Na}^{+}$and $\mathrm{Ca}^{2+}$ in either a Ca${ }^{2+}$ efflux or influx depending on the transmembrane ion gradient [Uehara et al., 2004]. There are 6 sodium/calciumpotassium exchangers (NCKX) coded by the Slc24a gene family (NCKX1-6 coded by Slc24a1-6, respectively) [Schnetkamp, 2004; Uehara et al., 2004]. NCKX1 was discovered in the outer segments of retinal rod photoreceptors, which extrude $\mathrm{Ca}^{2+}$ based on the $\mathrm{Na}^{+}$gradient, and at the same time requires $\mathrm{K}^{+}$cotransport [Schnetkamp et al., 1989]. The additional 5 NCKX proteins were shown to have a broader tissue distribution. NCKX2 is expressed in cone photoreceptors [Winkfein et al., 2003] and in neurons throughout the brain [Tsoi et al., 1998]. NCKX3 and NCKX4 proteins are abundant in the brain, but have a wide expression distribution [Tsoi et al., 1998; Li et al.,
2002]. The expression of NCKX 5 varied among different tissues, with a predominant level in the skin and eyes [Lamason et al., 2005]. NCKX6 (also known as NCLX; $\mathrm{Na}^{+}$/ $\mathrm{Ca}^{2+}-\mathrm{Li}^{+}$exchanger) displays a broad pattern of tissue expression including the brain, lung and heart, but its biological importance is unclear [Cai and Lytton, 2004]. Like the products of the $S l c 8 a$ gene family, the products of the Slc24a gene family are also bidirectional electrogenic transporters capable of exchanging $\mathrm{Na}^{+}$for $\mathrm{Ca}^{2+}, \mathrm{K}^{+}$in either a $\mathrm{Ca}^{2+}$ efflux or influx with a stochiometry of $4 \mathrm{Na}^{+}: 1 \mathrm{Ca}^{2+}, 1 \mathrm{~K}^{+}$[Li et al., 2002; Schnetkamp, 2004; Uehara et al., 2004].

Based on studies in a variety of tissues, $\mathrm{Na}^{+} / \mathrm{Ca}^{2+}$ exchangers demonstrated a tissue-specific expressed pattern. Recently the expression of NCX1 and NCX3 was demonstrated in ameloblasts [Okumura et al., 2010] and odontoblasts [Tsumura et al., 2010]. In this study, we present evidence for mRNA expression for all the $6 \mathrm{mem}$ bers of the Slc24a gene family in the developing mouse molar organ, with the highest expression by Slc24a4/ NCKX4. These data complement recently presented DNA array data indicating that in rat incisors NCKX4 is one of the most highly upregulated gene transcripts when maturation-stage enamel organ cells are compared to secretory-stage enamel organ cells [Lacruz et al., 2012a]. We further characterize the sublocalization of NCKX4 mRNA and protein in ameloblasts. Increased expression of NCKX4 mRNA in the late stages of amelogenesis suggests that it may have an important function in regulating $\mathrm{Ca}^{2+}$ transport during enamel maturation.

\section{Materials and Methods}

\section{Animals and Tissue Preparation}

Swiss Webster mice were treated in accordance with Institutional and Federal guidelines. For PCR and Western blot analysis, the mandibular first molars from mice on postnatal days 3, 6 and 9 were extracted. Using expression profiling of enamelin described elsewhere [Simmer et al., 2009], a specific secretory-stage enamel gene, it is inferred that in our sample, a maturation-stage ameloblast may only be identified on day 9 postnatal whereas ameloblasts at various secretory stages are readily identified on postnatal days 3 and 6 . It is estimated that on days 7-8 the mouse first molars are transitioning from a primarily secretory to a maturation function [Simmer et al., 2009]. The mandibles of 7-day-old mice were used for in situ hybridization. Brain and eye tissue were collected from adult mice and used as control tissues for mRNA expression analyses.

RT-PCR and Real-Time PCR

Total RNA was extracted from whole mandibular first molars of day-3, day- 6 and day-9 mice using RNeasy Mini Kit (Qiagen, 
Table 1. PCR primer design

\begin{tabular}{|c|c|c|}
\hline Gene product (symbol) & Primer sequence & Product size \\
\hline \multicolumn{3}{|l|}{ RT-PCR } \\
\hline \multirow[t]{2}{*}{ NCKX1 (Slc24a1) } & F: 5'-CACAGGAGAGGCGGTTACTC-3' & \multirow[t]{2}{*}{198} \\
\hline & R: 5'-CCACTGCCATTTCATTGTTG-3' & \\
\hline \multirow{2}{*}{ NCKX2 (Slc24a2) } & F: 5'-ATCTCCACCAAAGCCCCACAG-3' & \multirow{2}{*}{422} \\
\hline & R: 5'-CCCAATGACATGCAGAATGATGGC-3' & \\
\hline \multirow[t]{2}{*}{ NCKX3 (Slc24a3) } & F: 5'-CTATGGATCGCAGCCTTCTC-3' & \multirow[t]{2}{*}{301} \\
\hline & R: 5'-CGGAGTAGATGAGCCCTCTG-3' & \\
\hline \multirow[t]{2}{*}{ NCKX4 (Slc24a4) } & F: 5'-CTGGCTAAGAACTGCACAGATCCTG-3' & \multirow[t]{2}{*}{307} \\
\hline & R: 5'-CCACAATCGTTCCTACACCGACA-3' & \\
\hline \multirow[t]{2}{*}{ NCKX5 (Slc24a5) } & F: 5'-CTCTGACAACACCAGACTGCAGGA-3' & \multirow[t]{2}{*}{300} \\
\hline & R: 5'-ACCAGGGAAGACCTAGGCATAGCA-3' & \\
\hline \multirow[t]{2}{*}{ NCKX6 (Slc24a6) } & F: 5'-TTCACTGCACTCTATCTCGGC-3' & \multirow[t]{2}{*}{521} \\
\hline & R: 5'-ACAGGAAGGAGACCGCCGAT-3' & \\
\hline \multicolumn{3}{|l|}{ Real-time PCR (qPCR) } \\
\hline \multirow[t]{2}{*}{ NCKX1 } & F: 5'-GCCTACGCTCTCTATGTGTTC-3' & \multirow[t]{2}{*}{123} \\
\hline & R: 5'-ACTGGGCTTGCTGAGGTC-3' & \\
\hline \multirow[t]{2}{*}{ NCKX2 } & F: 5'-CCAACTTTACCGTCGAAGC-3' & \multirow[t]{2}{*}{113} \\
\hline & R: 5'-AGTGGGTCAAGGGTGTGTATC-3' & \\
\hline \multirow[t]{2}{*}{ NCKX3 } & F: 5'-GTCTTTGTCACGGTCTTTGG-3' & \multirow[t]{2}{*}{105} \\
\hline & R: 5'-GATGGAGAAACAGAGGAACAC-3' & \\
\hline \multirow[t]{2}{*}{ NCKX4 } & F: 5'-GTCGCTCTCACTGTCCTTG-3' & \multirow[t]{2}{*}{98} \\
\hline & R: 5'-AAGCACAGGAAGACAGCATAG-3' & \\
\hline \multirow[t]{2}{*}{ NCKX5 } & F: 5'-GCCTTCTTGGGTGTATTTATC-3' & \multirow[t]{2}{*}{128} \\
\hline & R: 5'-GAGAGTGTTGAAACCATGTTG-3' & \\
\hline \multirow[t]{2}{*}{ NCKX6 } & F: 5'-CTAGACTGCACTGGCTCTTTG-3' & \multirow[t]{2}{*}{92} \\
\hline & R: 5'-CCGTAATATGTTCACCACCTC-3' & \\
\hline \multirow[t]{2}{*}{$\beta$-actin } & F: 5'-GGGAAATCGTGCGTGACATC-3' & \multirow[t]{2}{*}{76} \\
\hline & R: 5'-GCGGCAGTGGCCATCTC-3' & \\
\hline \multicolumn{3}{|l|}{ In situ probe synthesis } \\
\hline \multirow[t]{2}{*}{ NCKX4 } & F: 5'-GGTCGACTTGATCAACTCAGCCAATGGTGTTA-3' & \multirow[t]{2}{*}{328} \\
\hline & R: 5'-GGGATCCTGATGAAGGTGACCATGAAGAA-3' & \\
\hline $\begin{array}{l}\text { Primers used the dete } \\
\text { NCKX2 and NCKX3 us } \\
\text { er RT-PCR primer seque } \\
\text { the AutoPrimer Bank ( } \\
\text { probe, the primers inclu } \\
\text { into plasmid pSP73. }\end{array}$ & $\begin{array}{l}\text { of NCKX family members in RT-PCR and real-time PCR. The p } \\
\text { RT-PCR followed the primer sequence reported before [Pyrski } \\
\text { were identified using MacVector software. Real-time primers we } \\
\text { //www.autoprime.de/AutoPrimeWeb). For the generation of th } \\
\text { SalI and BamHI site at their } 5^{\prime} \text { end (underlined) to aid in the su }\end{array}$ & $\begin{array}{l}\text { imers of NCKX1, } \\
\text { et al., 2007]. Oth- } \\
\text { e identified from } \\
\text { e NCKX4 in situ } \\
\text { bsequent cloning }\end{array}$ \\
\hline
\end{tabular}

Gaithersburg, Md., USA) as described previously [Lacruz et al., 2010a]. Total RNA was isolated from brain and eye tissue of adult mice to act as control tissues. Complementary DNA (cDNA) was generated from molars and control tissues using RETROscript ${ }^{\circledR}$ Kit (Ambion, Austin, Tex., USA). Gene-specific primers were synthesized for RT-PCR and real-time PCR (table 1). RT-PCR conditions were $95^{\circ} \mathrm{C}$ denaturation, $55^{\circ} \mathrm{C}$ annealing and $65^{\circ} \mathrm{C}$ extension times over 40 cycles and PCR-generated DNA products were resolved by electrophoresis on a $1.5 \%$ agarose gel.

For real-time PCR, molar cDNA was generated from $1 \mu \mathrm{g}$ RNA in a 20 - $\mu$ l reaction system using the QuantiTect Rev Transcription Kit (Qiagen Inc., Valencia, Calif., USA). Real-time PCR was per- formed with a C1000 TM Thermal (Bio-Rad Life Sciences, Hercules, Calif., USA). IQ SYBR Green Supermix Kit (Bio-Rad Life Sciences) was used in real-time PCR assays according to the manufacturer's protocol. Real-time PCR data was normalized to $\beta$-actin (Actb) mRNA using methods described in Schmittgen and Livak [2008]. Statistical analysis included multivariate analysis of variance (MANOVA) to assess whether the 6 dependent variables (gene variants) could distinguish the 3 experimental groups (days 3, 6 and 9). In the presence of a significant MANOVA, individual ANOVAs were run using the individual dependent variables. In the presence of a significant ANOVA post hoc Tukey's tests were performed to determine which group differences were significant. 


\section{In situ Hybridization}

The mandibles of 7-day-old postnatal mice were fixed with $4 \%$ paraformaldehyde, decalcified in 10\% EDTA solution for 14 days, embedded in Tissue-Tek ${ }^{\circledR}$ optimal cutting temperature compound, sectioned at $6 \mu \mathrm{m}$ thickness and mounted. A NCKX4-specific, 328 bp probe suitable for in situ hybridization was prepared from the unique central cytoplasmic loop of the encoded protein [Li et al., 2002] using primers listed in table 1 . This amplified region was subcloned into vector pSP73 (Promega Corporation, Madison, Wisc., USA). This vector was then digested with SalI and transcribed with SP6 RNA polymerase (Roche, Mannheim, Germany) to prepare the antisense probe;BamHI and T7 polymerase (Roche) were likewise used to get the NCKX4 sense (negative control) probe using digoxigenin-labeled RNA mixture (Roche). In situ hybridizations were performed following standard procedures [Wilkinson, 1992].

\section{Western Blot}

Mandibular first molars were isolated on days 3,6 and 9 and lysed in ice-cold RIPA buffer (Santa Cruz Biotechnology, Inc., Santa Cruz, Calif., USA) and sonicated on ice. The lysate was then centrifuged at $14,000 \mathrm{rpm}$ for $10 \mathrm{~min}$ at $4^{\circ} \mathrm{C}$, the protein-containing supernatant collected and the protein concentration determined. Total protein obtained from molars $(100 \mu \mathrm{g})$ were separated on $4-12 \%$ SDS-PAGE gels (Invitrogen, Carlsbad, Calif., USA) and then transferred to Immobilon-P membrane (Millipore, Bedford, Mass., USA). The membrane was incubated with polyclonal NCKX4-specific antibody (1:1,000 dilution; ProteinTech Group, Inc., catalogue \# 18992-1-AP), followed by incubation with HRP-conjugated goat anti-rabbit IgG (Santa Cruz Biotechnology). Proteins were visualized by SuperSignal West Chemiluminescent Substrate kit (Thermo Scientific, Rockford. Ill., USA). The optical densities of bands were determined using ImagineJ Software, and all data was normalized to the signal for $\beta$-actin (Sigma, St. Louis, Mo., USA; catalogue \# A1978).

\section{Immunohistochemistry}

Four 3-week-old Swiss Webster mice were anesthetized and perfused as follows. Lactated Ringer solution $(6-8 \mathrm{ml})$ was injected directly into the heart followed by injection of $15 \mathrm{ml}$ of fixative containing $4 \%$ paraformaldehyde, $0.1 \%$ glutaraldehyde in $0.08 \mathrm{M}$ sodium cacodylate buffer and $0.05 \%$ calcium chloride, $\mathrm{pH} 7.2-7.4$. The mandibles were dissected and soft tissues were removed and kept in the same fixative overnight. After washing the mandibles, they were decalcified in $4.13 \%$ disodium EDTA ( $\mathrm{pH} 7.3$ ) at $4^{\circ} \mathrm{C}$ for 3 weeks, embedded in paraffin and sectioned (approx. $5 \mu \mathrm{m}$ thick). Tissue sections were dewaxed and rehydrated and endogenous peroxidase was blocked with $0.3 \% \mathrm{H}_{2} \mathrm{O}_{2}$ in water. Sections were blocked with $1 \%$ bovine serum albumin and incubated overnight with anti-NCKX4 antibody produced in rabbit (1:50 dilution; Sigma-Aldrich, catalogue \# SAB2105562). This antibody was generated against a NCKX4 peptide region that has $100 \%$ identity between human and mouse. After washing, sections were incubated with a biotinylated anti-rabbit IgG secondary antibody (Vector Laboratories, Burlingame, Calif., USA). Sections were then incubated with the ready-to-use Vectastain Elite ABC reagent (Cat \# PK 7100) (Vector Laboratories) prior to incubation with AEC peroxidase substrate kit (Vector Laboratories, Cat\# SK-4200) as described in the protocol provided by the manufacturer. Sections were counter-stained with Mayer's hematoxylin, dehydrated through ethanol series, dewaxed and coverslipped.

\section{Results}

NCKX4 mRNA Expression Increases in Late Developmental Stages of Dental Formation

Gene-specific primers demonstrated expression of all 6 members of the Slc24a gene family (NCKX1-6) in the molars of 3-day-old mice (fig. 1A). Mouse eye cDNA was used as a positive control tissue for NCKX1 and NCKX5, while whole brain cDNA served as a control tissue for NCKX2, NCKX3, NCKX4 and NCKX6 [Cai and Lytton, 2004; Schnetkamp, 2004]. The sizes of all amplified DNA were as expected, with only a single product in each case. mRNA expression levels in mandibular first molars, relative to $\beta$ actin, were determined for each of the Slc24a genes on days 3, 6 and 9 using real-time PCR (fig. 1B). MANOVA indicated significant group differences when all dependent variables (gene variant expressions) were considered together (Wilks Lambda $=0.000$; d.f. $=6,1 ; \mathrm{p}=0.019$ ). When comparing the expression levels of individual genes on days 3, 6 and 9, ANOVA showed significant group differences for NCXK1, NCKX3, NCKX4 and NCKX5, but not for NCKX2 or NCKX6 (online suppl. table S1; www. karger.com/doi/10.1159/000337493). Comparing transcript levels for each gene at each time point revealed that NCKX1 expression was numerically lower on day 9 relative to days 3 and 6 , but a significant difference was only detected when comparing day 3 to day 9 ( $\mathrm{p} \leq 0.05)$. NKCX3 significantly decreased on day 9 relative to day 3 ( $\mathrm{p} \leq 0.05)$ but increased on day 6 relative to day 3 ( $\mathrm{p} \leq 0.05)$. NCKX4 and NCKX 5 expression increased sequentially throughout the developmental series sampled (from day 3 to day 9 ). For NCKX4, each increase in expression at each time point was significant $(\mathrm{p} \leq 0.005)$. For NCKX5, differences were significant when comparing day 3 to days 6 or 9 ( $p \leq 0.005$ ), but no significant difference was found between days 6 and $9(\mathrm{p}=0.931)$. Transcript fold changes are presented relative to the expression seen on day 6 (fig. 1C).

\section{Western Blot Analysis Shows Increased NCKX4 \\ Expression in 9-Day-Old Mice}

Western blot analysis was carried out with total protein isolated from mouse mandibular first molars on days 3, 6 and 9. NCKX4 protein was not detectable on day 3; however, NCKX4 was clearly evident on day 6 and this expression increases further on day 9 (fig. 1D). This procedure was repeated many times and the results were similar each time. Results from Western blot analysis were quantitated and normalized to the signal for $\beta$-actin (fig. 1E). For NCKX4, the fold changes seen at the protein level reflect a similar trend to that observed at the mRNA level. 


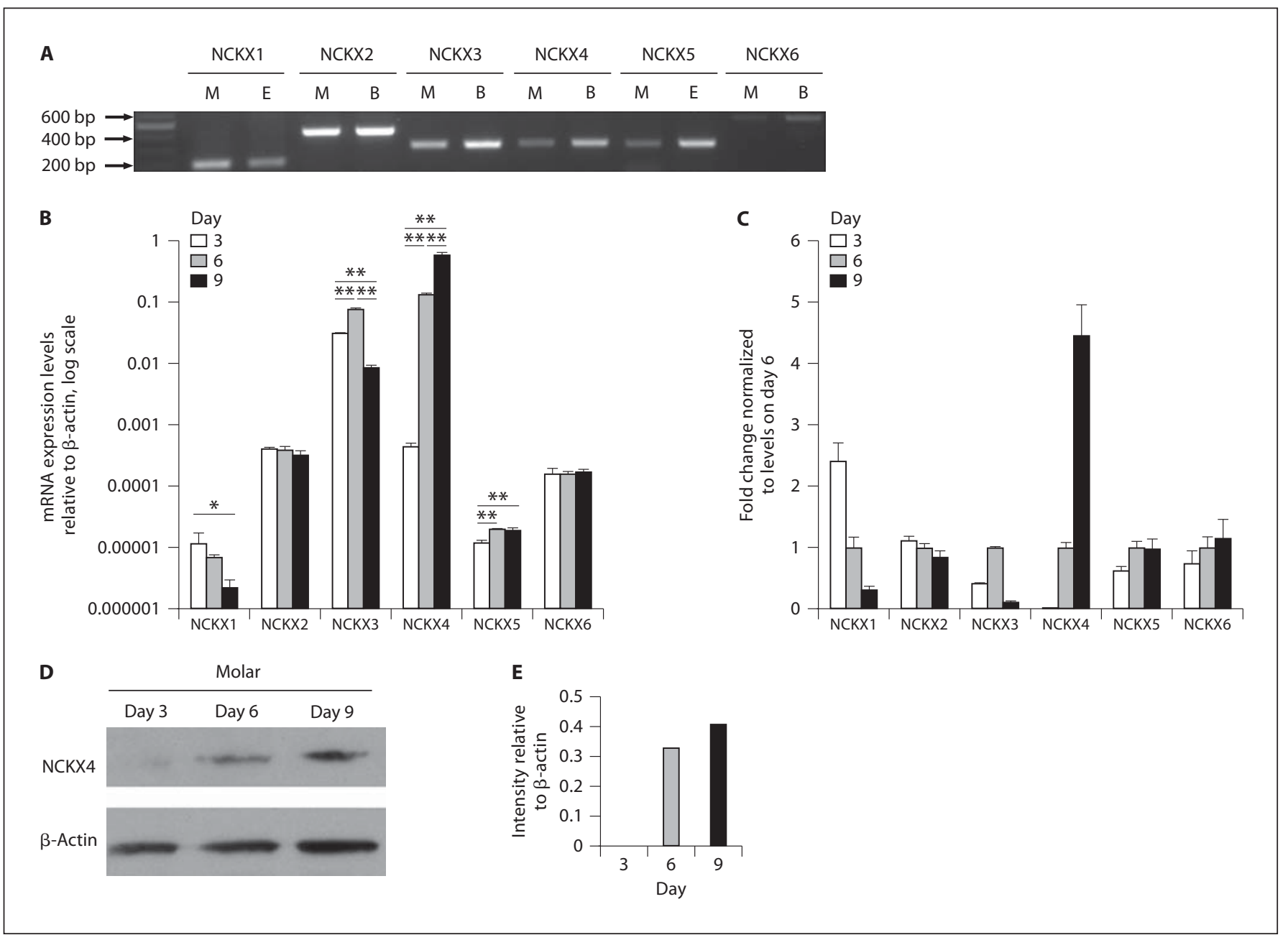

Fig. 1. Identification of Slc24a family members in mouse mandibular first molars isolated on days 3, 6 and 9. A All 6 Slc24a gene transcripts could be amplified by standard RT-PCR from 3-dayold mandibular first molars (M). Amplified fragments were of the predicted sizes (NCKX1, 198 bp; NCKX2, 422 bp; NCKX3, 301 bp; NCKX4, 307 bp; NCKX5, 300 bp; NCKX6, 521 bp). Control tissues included were brain (B) and eye (E). A DNA marker was included on the left of A. B The mRNA expression level for Slc24a family members in the 3-, 6- and 9-day-old molars were examined using real-time PCR. Messenger RNA levels were normalized to $\beta$-actin using the delta $C_{T}$ method. Statistical significance was assessed using ANOVA, and the post hoc Tukey's significant-differ-

\section{In situ Hybridization Identifies NCKX4 in}

Ameloblasts during the Late Stages of Amelogenesis

To characterize the spatial mRNA expression of NCKX4 in the developing tooth organ, in situ hybridization was performed on a 7-day-old mouse mandibular incisor (fig. 2A, C-F) and mandibular first molar (fig. 2G, I). Cytoplasmic expression of NCKX4 mRNA in amelo- ence test was used to assess which group differences were significant $\left({ }^{*} \mathrm{p}<0.05\right.$ and $\left.{ }^{* *} \mathrm{p}<0.01\right)$. Normalized mRNA levels were log-transformed for graphical representation (B). C Fold changes of the mRNA expression level for Slc24a genes calculated using the 2(-Delta Delta $\mathrm{C}(\mathrm{T})$ ) method normalizing transcript levels relative to values on day 6. D Western blot analysis for NCKX4 expression in mouse mandibular first molars isolated on days 3, 6 and 9. The band size seen for NCKX4 was of predicted size, being approximately $75 \mathrm{kDa}$. Levels of $\beta$-actin in each sample serve as a control. E Protein levels noted in $\mathbf{D}$ were quantitated by laser densitometry, and normalized against $\beta$-actin expression.

blasts was absent in the presecretory and early secretory stage (fig. 2C, D), becoming evident during the late secretory stage (fig. 2E) and being most highly expressed during the maturation stage (fig. $2 \mathrm{~F}$ ). This expression profile is also seen in molar ameloblasts where no expression is noted in presecretory ameloblasts located at, or in close proximity to the cervical loop (fig. 2G), with highest ex- 

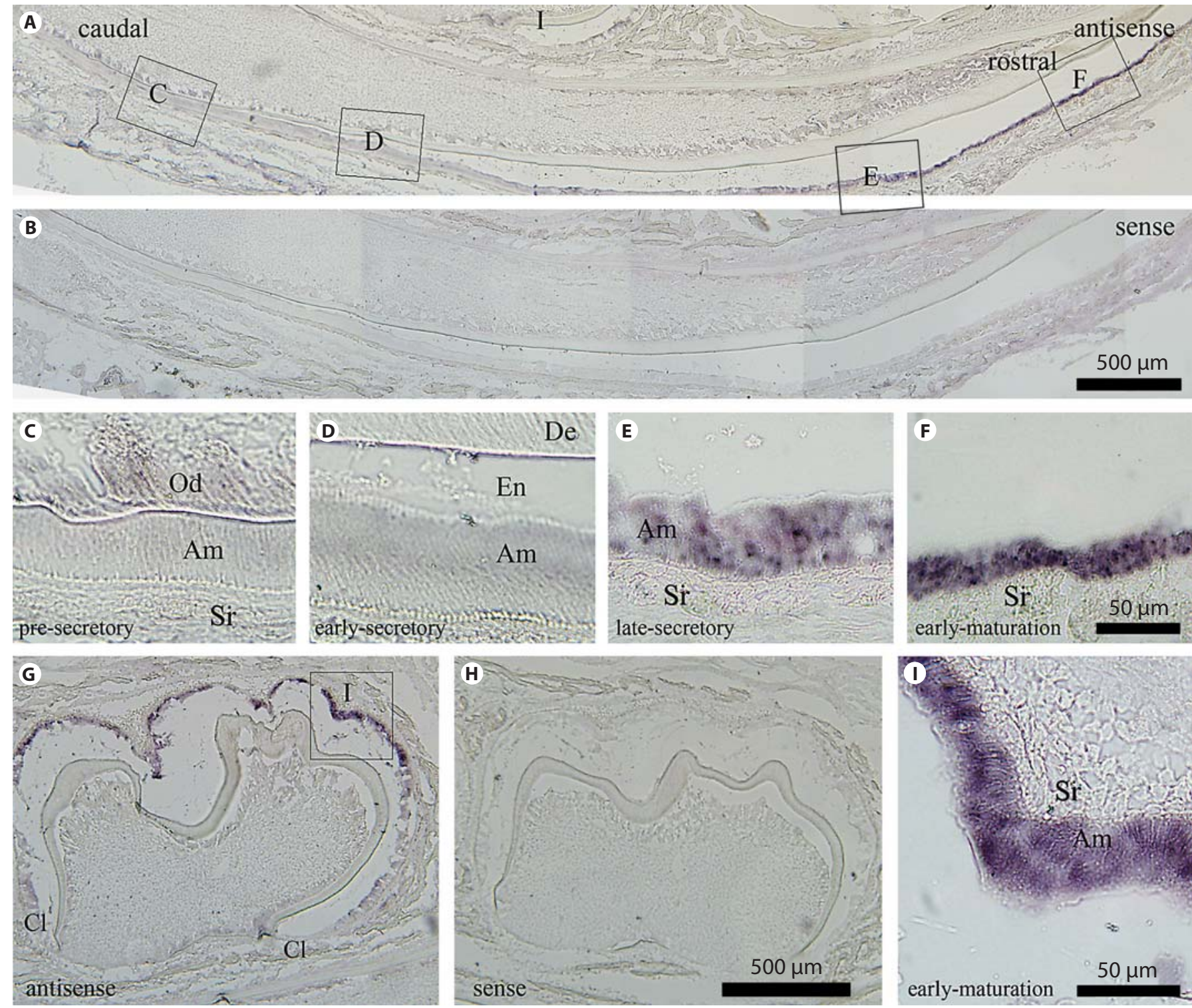

Fig. 2. In situ hybridization analysis of NCKX4 in the developing mandibular dentition of a 7-day-old mouse. Mouse incisors (A-F) and molars (G-I) in sagittal section using the antisense riboprobe (A, C-F, G, I) versus the sense (negative control) riboprobe (B, H). No hybridization signal is evident in the negative control sections. $\mathbf{C}-\mathbf{F}, \mathbf{I}$, are enlarged regions identified in $\mathbf{A}$ and $\mathbf{G}$. Ameloblast cell populations are presecretory $(\mathbf{C})$, early-secretory (D), late-secreto-

pression at the cusp tip (fig. 2G, I). Data also show some expression of NCKX4 in cell populations other than latesecretory-stage and maturation-stage ameloblasts; being weakly expressed in the cells of the papillary layer (e.g. cells of the stellate reticulum) and in odontoblasts. The sense probe (negative control) gave no signal (fig. $2 \mathrm{~B}, \mathrm{H}$ ).

ry (E) and early-maturation (F, I). The highest level of NCKX4 mRNA is seen during late-secretory and maturation-stage amelogenesis as evidenced in the incisors ( $\mathbf{E}$ and $\mathbf{F}$ compared to $\mathbf{C}$ and D) and in the molar (I). Am = Ameloblasts; $\mathrm{Cl}=$ cervical loop; $\mathrm{De}=$ dentin; $\mathrm{En}=$ enamel; $\mathrm{Od}=$ odontoblasts; $\mathrm{Sr}=$ stellate reticulum. A, B, G, H Scale bars: $500 \mu \mathrm{m}$. C-F, I Scale bars: $50 \mu \mathrm{m}$.

The in situ data presented here is consistent with our realtime PCR results that show NCKX4 mRNA levels more highly expressed on day 9 when maturation-stage ameloblasts are found in relatively large quantities in the tooth organ. 
Immunolocalization Identifies NCKX4 in

Ameloblasts and the Papillary Layer Cells during

Maturation-Stage Amelogenesis

Using the polyclonal antibody generated against an Nterminal peptide region of NCKX4 (Sigma-Aldrich) on the incisors of 3-week-old mice, the expression of NCKX4 was largely restricted to maturation-stage enamel organ cells, and most prominently in mid-late maturation-stage ameloblasts (fig. 3B-D). Lighter staining was noted in the overlying papillary layer cells (fig. 3B, C). Observing the same section prepared and processed in an identical manner, no NCKX4 expression was noted in the presecretory-stage (data not shown) or secretory-stage enamel organ cells (fig. 3A). Using secondary antibody only, no background staining was observed in the control tissue of maturation ameloblasts (fig. 3E). Spatially, within maturation ameloblasts, greater NCKX4 expression was noted at the apical poles (fig. 3B-D) and at the lateral membranes proximal to the apical ends (fig. 3D). In addition, NCKX4 is expressed in odontoblast cells (fig. 3F). An additional control included skeletal muscle known to express NCKX4 [Li et al., 2002] (fig. 3H). In figure 3, G and I are included as additional controls (no primary antibody) for odontoblast and pulp tissues and skeletal muscle, respectively.

\section{Discussion}

$\mathrm{Na}^{+} / \mathrm{Ca}^{2+}$ exchangers contribute to calcium transport in many tissues, including the tooth organ as discussed recently for NCX1 and NCX3 [Okumura et al., 2010; Tsumura et al., 2010]. In this study, we demonstrate that NCKX4 is expressed in late secretory-stage and maturation-stage ameloblasts, with significantly increased mRNA and protein expression during the late stages of amelogenesis. Calcium handling is a critical activity of ameloblasts in order to meet the needs of enamel Hap biomineralization [Smith, 1998; Hubbard, 2000]. Relatively high $\mathrm{Ca}^{2+}$ deposition was found during maturation-stage amelogenesis, as demonstrated by ${ }^{45} \mathrm{Ca}$ tracer [Takano, 1994, 1995], radiographic [Suga, 1982] and chemical analysis [Robinson et al., 1978]. Therefore, ameloblasts must adjust their function to allow for $\mathrm{Ca}^{2+}$ transport to the enamel matrix at a rate that meets requirements for crystal growth.

In this study, we identified that the expression of NCKX4 in the enamel organ is primarily restricted to the ameloblasts, being most highly expressed in maturationstage ameloblasts. Some expression is also noted in the
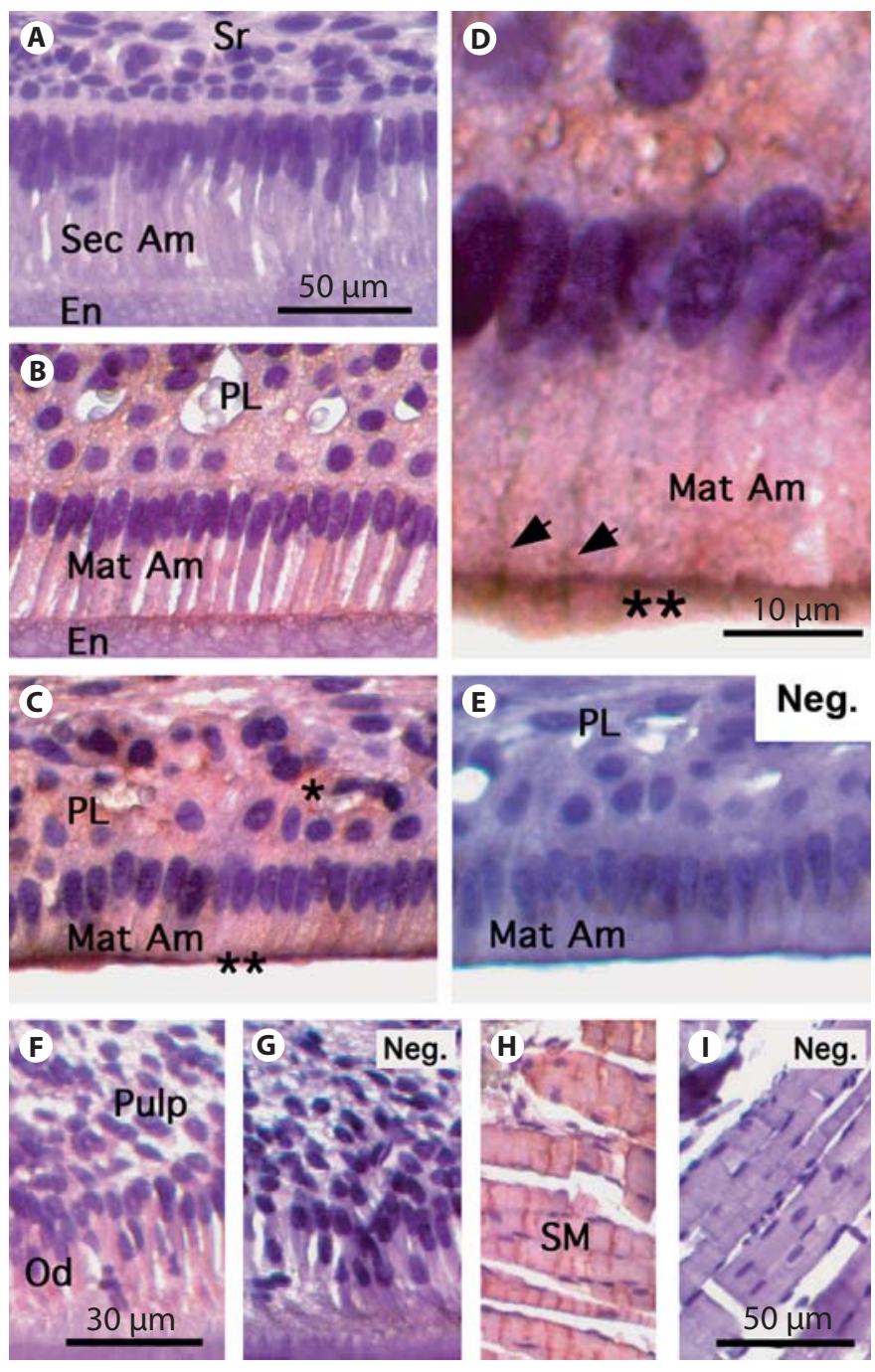

Fig. 3. NCKX4 immunolocalization in the developing mandibular incisor of a 3-week-old mouse. A No NCKX4 staining was visible in secretory-stage ameloblasts. B Staining is evident at the apical pole of early maturation-stage ameloblasts. Weak staining is also visible in the papillary layer (PL). C Mid-late maturation-stage ameloblasts and PL stain for NCKX4 with stronger signals detected at the apical pole of ameloblasts identified by double asterisks $\left({ }^{* *}\right)$. D Higher magnification $(\times 100)$ image of mid-late maturation-stage ameloblasts showing strong reactivity at apical pole as marked by double asterisks, and extending to the lateral membranes (arrowheads). E Negative control: mid-late maturation-stage ameloblasts were incubated with no primary NCKX4 antibody but all other steps were performed. No positive staining was visible in this tissue section. F, G Odontoblasts showed positive staining when incubated with NCKX4 (F), whereas the negative control (no primary antibody) showed no staining (G). H, I Skeletal muscle (tissue control): $\mathbf{H}$ shows positive staining, but the negative control (no primary antibody) did not stain (I). En = enamel; Mat Am = maturation ameloblasts; Neg. = no primary antibody; Od = odontoblasts; $\mathrm{PL}=$ papillary layer; Sec Am = secretory ameloblasts; SM = skeletal muscle; $\mathrm{Sr}=$ stellate reticulum. A-C, E, H, I Scale bars: $50 \mu \mathrm{m}$. D Scale bar: $10 \mu \mathrm{m}$. F, G Scale bars: $30 \mu \mathrm{m}$. 
papillary layer cells during enamel maturation. Given the increase requirements for $\mathrm{Ca}^{2+}$ transport during maturation [Smith, 1998; Hubbard, 2000] and the spatiotemporal expression pattern of NCKX4 described here, it is likely that NCKX4 participates in $\mathrm{Ca}^{2+}$ transport during this critical period. NCKX4 is a bidirectional transporter capable of exchanging $\mathrm{Na}^{+} / \mathrm{Ca}^{2+}-\mathrm{K}^{+}$in either a $\mathrm{Ca}^{2+}$ efflux or influx depending on the transmembrane ion gradient [Li et al., 2002; Schnetkamp, 2004; Uehara et al., 2004]. Thus, the function(s) of NCKX4 during amelogenesis can be delineated into at least 3 possible scenarios. First, NCKX4 may be involved in $\mathrm{Ca}^{2+}$ export from the ameloblasts into the forming enamel, i.e. supporting and/or duplicating the activities of NCX1 and NCX3 [Okumura et al., 2010]. Based on the immunohistochemical data presented here, where greater expression of NCKX4 is observed at the apical poles and the lateral membranes proximal to the apical ends of maturation-stage ameloblasts, this is a preferred scenario. Secondly, NCKX4 may facilitate $\mathrm{Ca}^{2+}$ import from the papillary layer. This scenario is also possible, based on the absolute need for $\mathrm{Ca}^{2+}$ in the formation of enamel crystals and the fact that other known NCX (NCX1 and
NCX3) are localized to the apical pole of maturationstage ameloblasts [Okumura et al., 2010]; however, the immunohistochemical data does not support such activity. A third alternative, but possibly the least likely, is that NCKX4 participates in both import and export activities during amelogenesis.

This study contributes to the knowledge of the roles of NCXs in enamel formation. In particular, NCKX4 expression was negligible or absent during early amelogenesis and is highly upregulated during the maturation stage. The expression of NCKX4 in enamel epithelial cells suggests a function in transcellular $\mathrm{Ca}^{2+}$ movement during enamel Hap formation.

\section{Acknowledgments}

The authors would like to thank Dr. Joseph J. Miller for his assistance with the statistical analyses and Drs. Malcolm Snead and Michael Hubbard for their continued discussions related to this and other ongoing projects of mutual interest. This work was supported by grant DE019629 from the National Institutes of Health.

\section{References}

Cai, X., J. Lytton (2004) Molecular cloning of a sixth member of the K+-dependent $\mathrm{Na}+1$ $\mathrm{Ca} 2+$ exchanger gene family, NCKX6. J Biol Chem 279: 5867-5876.

Franklin, I.K., R.A. Winz, M.J. Hubbard (2001) Endoplasmic reticulum Ca2+-ATPase pump is up-regulated in calcium-transporting dental enamel cells: a non-housekeeping role for SERCA2b. Biochem J 358: 217-224.

-Hubbard, M.J. (1995) Calbindin28kDa and calmodulin are hyperabundant in rat dental enamel cells. Identification of the protein phosphatase calcineurin as a principal calmodulin target and of a secretion-related role for calbindin $28 \mathrm{kDa}$. Eur J Biochem 230: $68-79$.

Hubbard, M.J. (1996) Abundant calcium homeostasis machinery in rat dental enamel cells. Up-regulation of calcium store proteins during enamel mineralization implicates the endoplasmic reticulum in calcium transcytosis. Eur J Biochem 239: 611-623.

Hubbard, M.J. (2000) Calcium transport across the dental enamel epithelium. Crit Rev Oral Biol Med 11: 437-466.
Josephsen, K., Y. Takano, S. Frische, J. Praetorius, S. Nielsen, T. Aoba, O. Fejerskov (2010) Ion transporters in secretory and cyclically modulating ameloblasts: a new hypothesis for cellular control of preeruptive enamel maturation. Am J Physiol Cell Physiol 299: C1299-1307.

Lacruz, R.S., M. Hilvo, I. Kurtz, M.L. Paine (2010a) A survey of carbonic anhydrase mRNA expression in enamel cells. Biochem Biophys Res Commun 393: 883-887.

Lacruz, R.S., A. Nanci, I. Kurtz, J.T. Wright, M.L. Paine (2010b) Regulation of $\mathrm{pH}$ during amelogenesis. Calcif Tissue Int 86: 91-103.

Lacruz, R.S., A. Nanci, S.N. White, X. Wen, H. Wang, S.F.Zalzal, V.Q. Luong, V.L. Schuetter, P.S. Conti, I. Kurtz, M.L. Paine (2010c) The sodium bicarbonate cotransporter (NBCel) is essential for normal development of mouse dentition. J Biol Chem 285: 24432-24438.

Lacruz, R.S., C.E. Smith, P. Bringasjr, Y.B. Chen, S.M. Smith, M.L. Snead, I. Kurtz, J.G. Hacia, M.J. Hubbard, M.L. Paine (2012a) Identification of novel candidate genes involved in mineralization of dental enamel by genomewide transcript profiling. J Cell Physiol 227: 2264-2275.
Lacruz, R.S., C.E. Smith, P. Moffatt, E.H. Chang, T.G. Bromage, P. Bringas, Jr., A. Nanci, S.K. Baniwal, J. Zabner, M.J. Welsh, I. Kurtz, M.L. Paine (2012b) Requirements for ion and solute transport, and $\mathrm{pH}$ regulation, during enamel maturation. J Cell Physiol 227: 17761785.

Lamason, R.L., M.A. Mohideen, J.R. Mest, A.C. Wong, H.L. Norton, M.C. Aros, M.J. Jurynec, X. Mao, V.R. Humphreville, J.E. Humbert, S. Sinha, J.L. Moore, P. Jagadeeswaran, W. Zhao, G. Ning, I. Makalowska, P.M. McKeigue, D. O’Donnell, R. Kittles, E.J. Parra, N.J. Mangini, D.J. Grunwald, M.D. Shriver, V.A. Canfield, K.C. Cheng (2005) SLC24A5, a putative cation exchanger, affects pigmentation in zebrafish and humans. Science 310: 1782-1786.

Li, X.F., A.S. Kraev, J. Lytton (2002) Molecular cloning of a fourth member of the potassium-dependent sodium-calcium exchanger gene family, NCKX4. J Biol Chem 277: 48410-48417.

Linde, A. (1995) Dentin mineralization and the role of odontoblasts in calcium transport. Connect Tissue Res 33: 163-170. 
Okumura, R., Y. Shibukawa, T. Muramatsu, S. Hashimoto, K. Nakagawa, M. Tazaki, M. Shimono (2010) Sodium-calcium exchangers in rat ameloblasts. J Pharmacol Sci 112: 223-230.

Paine, M.L., S.N. White, W. Luo, H. Fong, M. Sarikaya, M.L. Snead (2001) Regulated gene expression dictates enamel structure and tooth function. Matrix Biol 20: 273-292.

Pyrski, M., J.H. Koo, S.K. Polumuri, A.M. Ruknudin, J.W. Margolis, D.H. Schulze, F.L. Margolis (2007) Sodium/calcium exchanger expression in the mouse and rat olfactory systems. J Comp Neurol 501: 944-958.

$\checkmark$ Quednau, B.D., D.A. Nicoll, K.D. Philipson (2004) The sodium/calcium exchanger family-SLC8. Pflugers Arch 447: 543-548.

Robinson, C., P. Fuchs, D. Deutsch, J.A. Weatherell (1978) Four chemically distinct stages in developing enamel from bovine incisor teeth. Caries Res 12: 1-11.

-Schmittgen, T.D., K.J. Livak (2008) Analyzing real-time PCR data by the comparative $\mathrm{C}(\mathrm{T})$ method. Nat Protoc 3: 1101-1108.

Schnetkamp, P.P., D.K. Basu, R.T. Szerencsei (1989) $\mathrm{Na}+-\mathrm{Ca} 2+$ exchange in bovine rod outer segments requires and transports $\mathrm{K}+$. Am J Physiol 257: C153-157.
Schnetkamp, P.P. (2004) The SLC24 Na+/Ca2+$\mathrm{K}+$ exchanger family: vision and beyond. Pflugers Arch 447: 683-688.

Simmer, J.P., Y. Hu, R. Lertlam, Y. Yamakoshi, J.C. Hu (2009) Hypomaturation enamel defects in Klk4 knockout/LacZ knockin mice. J Biol Chem 284: 19110-19121.

Smith, C.E. (1998) Cellular and chemical events during enamel maturation. Crit Rev Oral Biol Med 9: 128-161.

Suga, S. (1982) Progressive mineralization pattern of developing enamel during the maturation stage. J Dent Res Spec No.: 1532-1542.

Takano, Y. (1994) Histochemical aspects of calcium regulation by the enamel forming cells during matrix formation and maturation. Kaibogaku Zasshi 69: 106-122.

Takano, Y. (1995) Enamel mineralization and the role of ameloblasts in calcium transport. Connect Tissue Res 33: 127-137.

Tsoi, M., K.H. Rhee, D. Bungard, X.F. Li, S.L. Lee, R.N. Auer, J. Lytton (1998) Molecular cloning of a novel potassium-dependent sodium-calcium exchanger from rat brain. J Biol Chem 273: 4155-4162.
Tsumura, M., R. Okumura, S. Tatsuyama, H. Ichikawa, T. Muramatsu, T. Matsuda, A. Baba, K. Suzuki, H. Kajiya, Y. Sahara, M. Tokuda, Y. Momose, M. Tazaki, M. Shimono, Y. Shibukawa (2010) Ca2+ extrusion via $\mathrm{Na}+-\mathrm{Ca} 2+$ exchangers in rat odontoblasts. J Endod 36: 668-674.

Turnbull, C.I., K. Looi, J.E. Mangum, M. Meyer, R.J. Sayer, M.J. Hubbard (2004) Calbindin independence of calcium transport in developing teeth contradicts the calcium ferry dogma. J Biol Chem 279: 55850-55854.

Uehara, A., T. Iwamoto, Y. Nakamura, I. Imanaga (2004) Forefront of $\mathrm{Na}+/ \mathrm{Ca} 2+$ exchanger studies: physiology and molecular biology of monovalent cation sensitivities in $\mathrm{Na}+/ \mathrm{Ca} 2+$ exchangers. J Pharmacol Sci 96: 19-22.

Wilkinson, D.G. (1992) In Situ Hybridization: A Practical Approach. (IRL Press) Oxford University Press, Oxford.

Winkfein, R.J., R.T. Szerencsei, T.G. Kinjo, K. Kang, M. Perizzolo, L. Eisner, P.P. Schnetkamp (2003) Scanning mutagenesis of the alpha repeats and of the transmembrane acidic residues of the human retinal cone $\mathrm{Na} /$ Ca-K exchanger. Biochemistry 42: 543-552. 